\title{
Growth hormone treatment in the pre-transplant period is associated with superior outcome after pediatric kidney transplantation
}

\author{
Celina Jagodzinski ${ }^{1}$ Sophia Mueller ${ }^{1} \cdot$ Rika Kluck $^{1} \cdot$ Kerstin Froede $^{1} \cdot$ Leo Pavičić $^{2}$. Jutta Gellermann ${ }^{3}$. \\ Dominik Mueller $^{3} \cdot$ Uwe Querfeld $^{3} \cdot$ Dieter Haffner $^{1} \cdot$ Miroslav Zivicnjak $^{1}$ (D)
}

Received: 28 May 2021 / Revised: 6 July 2021 / Accepted: 6 July 2021 / Published online: 20 September 2021

(c) The Author(s) 2021, corrected publication 2022

\begin{abstract}
Background Recombinant human growth hormone (rhGH) is frequently used for treatment of short stature in children with chronic kidney disease (CKD) prior to kidney transplantation (KT). To what extent this influences growth and transplant function after KT is yet unknown.

Methods Post-transplant growth (height, sitting height, leg length) and clinical parameters of $146 \mathrm{CKD}$ patients undergoing KT before the age of 8 years, from two German pediatric nephrology centers, were prospectively investigated with a mean follow-up of 5.56 years. Outcome in patients with (rhGH group) and without (non-prior rhGH group) prior rhGH treatment was assessed by the use of linear mixed-effects models.

Results Patients in the rhGH group spent longer time on dialysis and less frequently underwent living related KT compared to the non-prior rhGH group but showed similar height $z$-scores at the time of KT. After KT, steroid exposure was lower and increments in anthropometric $z$-scores were significantly higher in the rhGH group compared to those in the non-prior rhGH group, although $18 \%$ of patients in the latter group were started on rhGH after KT. Non-prior rhGH treatment was associated with a faster decline in transplant function, lower hemoglobin, and higher C-reactive protein levels (CRP). After adjustment for these confounders, growth outcome did statistically differ for sitting height $z$-scores only.

Conclusions Treatment with rhGH prior to KT was associated with superior growth outcome in prepubertal kidney transplant recipients, which was related to better transplant function, lower CRP, less anemia, lower steroid exposure, and earlier maturation after KT.
\end{abstract}

Keywords Children $\cdot$ Growth hormone $\cdot$ Kidney transplantation $\cdot$ Growth $\cdot$ Kidney function $\cdot$ Development

\section{Introduction}

Kidney transplantation (KT) is the therapy of choice in pediatric patients with chronic kidney disease (CKD) stage 5 [1]. However, it only manages to correct the disturbances associated with CKD to a certain extent. Indeed, disproportionate short

Miroslav Zivicnjak

zivicnjak.miroslav@mh-hannover.de

1 Department of Pediatric Kidney, Liver and Metabolic Diseases, Children's Hospital, Hannover Medical School, Carl-Neuberg-Str. 1, 30625 Hannover, Germany

2 Zagreb, Croatia

3 Department of Pediatrics, Division of Gastroenterology, Nephrology and Metabolic Diseases, Charité

- Universitätsmedizin Berlin, Campus Virchow-Klinikum, Augstenburger Platz 1, 13353 Berlin, Germany stature with preferential impairment of leg growth is a given in children with CKD stage 5 and catch-up growth after KT is usually limited [2]. Recent studies still report reduced adult height in patients with childhood-onset CKD stage 5 in about $40 \%$ of patients despite successful KT [3]. Growth outcome after KT is associated with many factors including patient age, transplant function, steroid exposure, parental height, birth parameters, and initial degree of growth retardation [3-8]. Careful control of caloric intake, metabolic disturbances including acidosis, and the CKD mineral and bone disorder (CKD-MBD), is of utmost importance to achieve optimal height at the time of KT, which is significantly associated with adult height $[4,9]$. In addition, treatment with recombinant human growth hormone (rhGH) is a proven measure to improve growth in short children with CKD stages 3-5D [10]. However, rhGH is currently underutilized in short children with CKD stage 5 in North America and many European countries, which is partly due to family 
refusal, non-adherence, and lack of reimbursement by insurance companies [11-14]. Its use after KT was also shown to be effective but concern has been raised that it may promote rejection episodes and thereby impair long-term graft function [15]. At present, discontinuation of rhGH therapy at the time of KT is standard practice. The currently recommended strategy for optimizing post-transplant growth consists of steroid-minimizing immunosuppressive protocols and monitoring of spontaneous growth after KT for at least 12 months before considering rhGH treatment $[10,16]$. Whether treatment with rhGH prior to KT has long-term effects on growth and clinical features after KT has not been investigated. Therefore, we evaluated post-transplant growth in 146 prepubertal kidney allograft recipients who received rhGH treatment prior to $\mathrm{KT}$ or not.

\section{Methods}

\section{Study design and patients}

From May 1998 until January 2020, a total of 947 children who received KT were enrolled in the CKD Growth and Development Study. This is a prospective observational cohort study in two pediatric nephrology centers in Germany (Hannover Medical School and Charité Universitätsmedizin, Berlin) assessing growth and clinical parameters of all available CKD patients stages 3-5D and after KT in yearly intervals as previously described [2]. The study was approved by the local ethics committees, and research was performed in accordance with the Declaration of Helsinki. Study participants and/or their parents gave their consent prior to participation.

For this analysis, all first time graft recipients who underwent KT before the age of 8 years and with at least one valid follow-up examination were included until the age of 18 years. Primary diseases included congenital anomalies of the kidney and urinary tract (59\%), glomerulopathies (25\%), and others $(16 \%)$. Patients with syndromic diseases, e.g., Jeune syndrome $(n=2)$, Schimke $(n=2)$, Prune-Belly syndrome $(n=1)$, Arimas syndrome $(n=1)$, and Denys-Drash syndrome $(n=1)$, were excluded. In addition, we excluded patients who had to resume dialysis treatment after KT or who had to be re-transplanted $(n=21)$, who underwent liver or heart transplantations $(n=6)$, or who had to be given rhGH before and after KT $(n=9)$. All annual follow-up interval measurements from immediately after KT (0.01-0.99 years) up to a maximum of $10(10.00-10.99)$ years after KT were included. Thus, the data of 146 patients (92 male), who underwent a total of 812 annual measurements, with a mean follow-up of 5.56 years could be analyzed.

Patients were divided in two groups: (i) patients who received rhGH prior to $\mathrm{KT}$ (rhGH group, $n=52$ ), and (ii) patients who received no rhGH prior to KT (non-prior rhGH group, $n=94)$. In 17 out of 94 patients $(18 \%)$ of the latter group, rhGH was started after KT, but in none of the former group. Indications for the use of rhGH prior to KT were a height SD score (SDS) $<-2.0$ and a height velocity $<25$ th percentile in patients with CKD stages 3-5D. The same auxological parameters were used as indications for use of rhGH post KT after a minimum follow-up of 12 months [10].

Primary immunosuppressive protocols included daily prednisolone treatment. By week 8 , the prednisolone dosage was tapered down to $4 \mathrm{mg} / \mathrm{m}^{2} /$ day. All patients were kept on daily prednisolone until 2007. From 2007 onwards, patients were regularly weaned off steroids between six and twelve months post KT in case of stable graft function and lack of rejection. The prescribed dietary intake was in accordance with targeted requirements. Dietary intake was routinely monitored in all CKD and transplanted patients every 3-12 months, depending on patient's age.

Genetic target height was calculated from mid-parental height: mother's height + father's height $/ 2 \pm 6.5 \mathrm{~cm}$ in boys and girls, respectively [17]. Data on gestational age were obtained from the children's health care booklets. The point of attainment of CKD stage 5 was defined by estimated glomerular filtration rate (eGFR) below $15 \mathrm{ml} / \mathrm{min} / 1.73 \mathrm{~m}^{2}$, initiation of dialysis, or pre-emptive KT (no prior dialysis). The revised Schwartz formula was used to calculate eGFR [18]. Newborns were classified as small for gestational age (SGA) if birth weight or length was $<10$ th percentile using national growth charts [19]. Anemia was defined using the World Health Organization age- and sex-specific hemoglobin thresholds for defining anemia in children [20]. There was no significant difference in age distribution of both groups in any year from directly after KT until end of follow-up. Bone age delay was calculated as the difference between bone age and chronological age as a measure of skeletal maturation.

\section{Anthropometry}

Anthropometric measurements included total body height, sitting height, and leg length, as described [21]. The sitting height index was calculated as the ratio between sitting height and stature as a measure of body disproportion. All measurements were performed by the same investigator (M. Z.), as recommended by the International Biological Program [22] with the use of standardized equipment (Dr. Keller, I Stadiometer-Limbach-Oberfrohna, Germany; Siber Hegner Anthropometer Zürich, Switzerland).

\section{Statistical analyses}

Data are given as mean \pm SD and/or $95 \%$ confidence interval (CI) unless indicated otherwise. SDS values for anthropometric parameters were calculated according to the equation $\mathrm{SDS}=\left(x_{\mathrm{i}}-x_{\mathrm{s}}\right) / \mathrm{SD}\left(x_{\mathrm{i}}\right.$ representing individual patient value, $x_{\mathrm{s}}$ as well as SD representing corresponding value from age- and 
sex-matched healthy reference peers) $[23,24]$. The normality of distribution was evaluated by the Shapiro-Wilk test for each cohort (time after KT) for each variable. Measurements were grouped according to time after KT and age cohorts using yearly intervals. Differences between groups were assessed by unpaired $t$ test or the Mann-Whitney $U$ test, as appropriate.

Linear mixed-effects models (Mixed) and the Kronecker product model were used to generate a time-dependent analysis of anthropometric and clinical data including both time after KT and age cohort as well as the factor treatment (rhGH versus non-prior rhGH). The combination of unstructured and autoregressive covariance matrix type (UN_AR1) turned out to be the most appropriate for our analyses. In addition, anthropometrical data were adjusted for covariates, i.e., age at CKD stage 5, age at KT, average daily steroid dosage, time after $\mathrm{KT}$, average eGFR, $\mathrm{pH}$, hemoglobin, and $\mathrm{HCO}_{3}$ values during the preceding 12 months. Clinical predicted determinants of kidney function after KT in the two treatment groups were adjusted for the following covariates: age at CKD stage 5 , age at KT, average daily steroid dosage, time after KT, and averages of hemoglobin, $\mathrm{pH}$, and $\mathrm{HCO}_{3}$ during the preceding year. The standard statistical package SPSS for Windows, version 26.0 (IBM Corp), was used for statistical calculations. Results were considered significant at a level of $p<0.05$.

\section{Results}

Clinical characteristics of the study cohorts are presented in Table 1. Patient groups did not differ with respect to sex, male-female incidence, age when CKD stage 5 was reached and KT, time of follow-up, genetic target height, rates of congenital CKD, pre-emptive KT, and SGA. However, patients in the rhGH group less frequently underwent living related KT (19\% versus 34\%) and spent longer time on dialysis (median, 1.47 years versus 0.78 years) (Table 1 ). Growth hormone therapy was initiated in the rhGH group at a median age of 1.93 years, continued over a median period of 1.23 years and was stopped in all patients at the time of KT. By contrast, after KT, rhGH treatment was initiated in the non-prior rhGH group (18\%) only. The mean time interval between KT and initiation of rhGH treatment in the patients who received rhGH after KT was 5.71 years. The rhGH group less frequently received treatment with erythropoietin, and less frequently showed anemia which was most pronounced during late post-transplant years $(p<0.05)$ (Table 1, Fig. 1).

\section{Post-transplant growth and maturation in patients with and without prior rhGH treatment}

Before KT, $z$-scores for anthropometric data did not differ significantly between groups and $61.3 \%$ and $67.9 \%$, respectively, of patients with and without prior rhGH treatment presented with short stature (<-2.0 SDS) (Fig. 2). After KT, a sustained and significant increase in mean standardized height was noted in patients with prior rhGH treatment (pre-KT, -2.08 SDS; 4 years post-KT, -1.11 ; $p<0.05$ ), whereas in patients without prior rhGH treatment the change of standardized height was significant only until 1 year post-KT (Fig. 2). Maximum discrepancy in stature between groups occurred 7 years after KT $(-0.85$ SDS versus -1.76 SDS, $p<0.05$ ). Consequently, patients with prior rhGH treatment were generally taller with respect to height, sitting height (each $p<0.05)$, and leg length $(p=0.081$, Table 2). This was mainly related to a more pronounced increase in leg length in early post-transplant years in the rhGH group, resulting in $z$-scores of -0.97 in the rhGH group and -1.67 in the non-prior rhGH group 5 years after KT ( $p<0.05$, Fig. 2$)$.

Consequently, the frequency of short stature after KT was lower in the rhGH group (35.7\% versus 50.0\%) which was most pronounced 7 years after KT $(11.1 \%$ versus $45.2 \%$, $p<0.01)$. Likewise, reduced sitting height and leg length $(<-2.0 \mathrm{SDS})$ were more frequently noted in the non-prior rhGH group which was also most pronounced 7 years after KT (sitting height, $24.4 \%$ versus $0.0 \%$; leg length, 48.8 versus $11.1 \%$; each $p<0.05$ ). By contrast, the mean standardized sitting height index was comparably elevated in both groups (Table 2).

The typical prepubertal peak of growth in stature and leg length occurred 5 years after KT in the rhGH group, whereas the non-prior rhGH group showed a delay in leg length and total body height, peaking 6 years after KT (Fig. 2). Instead, sitting height showed the same timing in growth gain in both groups, peaking 5 years after KT, but differing in growth intensity (rhGH group -0.41 versus non-prior rhGH group - 0.92 SDS).

Likewise, age at menarche occurred much later in the non-prior rhGH group than in the rhGH group (13.02 years versus 11.79 years, respectively, $p<0.05$, Table 1$)$. Mean bone age delay was comparable in both groups at last assessment before KT $(p=0.497)$, but was significantly more pronounced in the non-prior rhGH group after KT (rhGH group -0.71 years; non-prior rhGH group -1.23 years, $p<0.05$, Table 1, Fig. 3).

\section{Transplant function and biochemical parameters in patients with and without prior rhGH treatment}

Mean eGFR values were significantly higher in the rhGH group after KT overall $\left(71.21 \mathrm{ml} / \mathrm{min} / 1.73 \mathrm{~m}^{2}\right.$ versus $59.20 \mathrm{ml} / \mathrm{min} / 1.73 \mathrm{~m}^{2}$ ) (Table 1). Mean eGFR peaked 1 year and 2 years post-KT and amounted to $75 \mathrm{ml} /$ $\min / 1.73 \mathrm{~m}^{2}$ and $80 \mathrm{ml} / \mathrm{min} / 1.73 \mathrm{~m}^{2}$ in the non-prior rhGH group and the rhGH group, respectively (Fig. 4). 
Table. 1 Clinical characteristics of 146 pediatric kidney transplant recipients with or without rhGH treatment prior to transplantation

\begin{tabular}{|c|c|c|c|c|c|c|c|}
\hline & \multicolumn{3}{|l|}{ rhGH prior to $K T$} & \multicolumn{3}{|l|}{ No rhGH prior to $K T$} & \multirow[b]{2}{*}{$p$ value } \\
\hline & Incidence & & $\begin{array}{l}\text { No. of cases/ } \\
\text { measurements }\end{array}$ & Incidence & & $\begin{array}{l}\text { No. of cases/ } \\
\text { measurements }\end{array}$ & \\
\hline Male, $\%$ & 61.5 & & 32 of 52 & 63.8 & & 60 of 94 & 0.460 \\
\hline Congenital CKD, \% & 78.8 & & 41 of 52 & 77.7 & & 73 of 94 & 0.522 \\
\hline Preemptive KT, \% & 34.6 & & 18 of 52 & 33.0 & & 31 of 94 & 0.491 \\
\hline Living donor, $\%$ & 19.2 & & 10 of 52 & 34.0 & & 32 of 94 & 0.042 \\
\hline SGA history, $\%$ & 32.7 & & 16 of 49 & 24.7 & & 19 of 77 & 0.220 \\
\hline Epo therapy, \% & 22.8 & & 71 of 312 & 28.4 & & 142 of 500 & 0.044 \\
\hline Iron therapy, $\%$ & 32.7 & & 102 of 312 & 35.4 & & 160 of 500 & 0.448 \\
\hline $\begin{array}{l}\text { Vit. D/calcimimetics/ } \\
\text { phosphate binders, \% }\end{array}$ & 41.3 & & 129 of 312 & 35.7 & & 177 of 500 & 0.052 \\
\hline Acidosis therapy, $\%$ & 40.8 & & 125 of 306 & 40.5 & & 201 of 496 & 0.493 \\
\hline Anemia, $\%$ & 41.0 & & 127 of 310 & 52.1 & & 257 of 493 & 0.001 \\
\hline $\begin{array}{l}\text { Non-repeated measure- } \\
\text { ments }{ }^{a}\end{array}$ & Median $(I Q R)$ & Min.--max & No. of cases & median $(I Q R)$ & Min.--max & No. of cases & \\
\hline Age at KT, years & $4.26(2.78-5.55)$ & $1.35-7.73$ & 52 of 52 & $3.68(2.04-5.93)$ & $0.49-7.98$ & 94 of 94 & 0.529 \\
\hline $\begin{array}{l}\text { Duration after KT, } \\
\text { years }\end{array}$ & $7.51(4.23-10.09)$ & $0.06-10.88$ & 52 of 52 & $8.33(4.74-10.14)$ & $0.06-10.93$ & 94 of 94 & 0.608 \\
\hline $\begin{array}{l}\text { Age at dialysis initia- } \\
\text { tion, years }\end{array}$ & $2.05(0.74-4.36)$ & $0.01-7.40$ & 35 of 52 & $1.92(0.61-4.33)$ & $0.01-7.81$ & 63 of 94 & 0.956 \\
\hline $\begin{array}{l}\text { Age at CKD stage } 5, \\
\text { years }\end{array}$ & $2.94(1.49-4.90)$ & $0.01-7.40$ & 52 of 52 & $2.98(0.94-5.15)$ & $0.01-7.87$ & 94 of 94 & 0.851 \\
\hline $\begin{array}{l}\text { Duration of dialysis, } \\
\text { years }\end{array}$ & $1.47(0.74-2.35)$ & $0.01-4.71$ & 36 of 52 & $0.78(0.46-1.66)$ & $0.03-4.75$ & 64 of 94 & 0.011 \\
\hline $\begin{array}{l}\text { Genetic target height, } \\
\text { SDS }\end{array}$ & $-0.10(-0.67-0.42)$ & $-2.28-1.46$ & 50 of 52 & $-0.13(-0.67-0.42)$ & $-2.93-1.39$ & 89 of 94 & 0.961 \\
\hline Menarche, age & $11.79(11.13-12.24)$ & $10.74-12.97$ & 8 of 20 & $13.02(12.80-13.50)$ & $10.21-13.70$ & 7 of 44 & 0.040 \\
\hline $\begin{array}{l}\text { Age at start of rhGH } \\
\text { therapy, years }\end{array}$ & $1.93(1.27-4.13)$ & $0.27-6.31$ & 52 of 52 & & & & \\
\hline $\begin{array}{c}\text { Duration of rhGH } \\
\text { treatment, years }\end{array}$ & $1.23(0.59-2.23)$ & $0.11-5.39$ & 52 of 52 & & & & \\
\hline $\begin{array}{l}\text { Repeated measure- } \\
\text { ments }^{b}\end{array}$ & $\begin{array}{l}\text { Estimated marginal } \\
\text { mean }(95 \% \text { CI) }\end{array}$ & Min.-max & $\begin{array}{l}\text { No. of meas- } \\
\text { urements }\end{array}$ & $\begin{array}{l}\text { Estimated marginal } \\
\text { mean }(95 \% \mathrm{CI})\end{array}$ & Min.-max & $\begin{array}{l}\text { No. of meas- } \\
\text { urements }\end{array}$ & \\
\hline $\begin{array}{l}\text { eGFR, } \mathrm{mL} / \mathrm{min} \text { per } \\
1.73 \mathrm{~m}^{2 A A}\end{array}$ & $71.21(63.55-78.87)$ & $4.74-147.40$ & 301 of 312 & $59.20(53.40-64.99)$ & $8.53-190.54$ & 474 of 500 & 0.018 \\
\hline $\begin{array}{l}\text { Steroid dosage, } \mathrm{mg} / \\
\text { kg per day }{ }^{A A}\end{array}$ & $0.04(0.03-0.05)$ & $0.00-0.33$ & 303 of 312 & $0.06(0.05-0.07)$ & $0.00-0.49$ & 476 of 500 & 0.016 \\
\hline $\begin{array}{c}\text { Plasma } \mathrm{HCO}_{3}, \\
\mathrm{mmol} / \mathrm{L}^{A A}\end{array}$ & $22.39(22.06-22.72)$ & $18.53-31.55$ & 304 of 312 & $22.72(22.48-22.97)$ & $18.30-28.32$ & 476 of 500 & 0.106 \\
\hline $\mathrm{Hb}, \mathrm{g} / \mathrm{dL}^{A A}$ & $11.48(11.20-11.76)$ & $6.50-14.90$ & 306 of 312 & $11.39(11.15-11.63)$ & $7.52-15.53$ & 480 of 500 & 0.623 \\
\hline PTH, ng/l & $89.00(74.17-103.83)$ & $1.12-641.30$ & 259 of 312 & $89.80(79.18-100.43)$ & $5.50-708.00$ & 420 of 500 & 0.930 \\
\hline CRP, mg/l & $2.08(1.39-2.76)$ & $0.00-50.00$ & 69 of 312 & $5.59(2.62-8.57)$ & $0.04-133.95$ & 67 of 500 & 0.026 \\
\hline Bone age delay, years & $\begin{array}{l}-0.71(-1.05 \\
\text { to }-0.37)\end{array}$ & $-3.34-2.56$ & 130 of 312 & $\begin{array}{l}-1.23(-1.51 \\
\text { to }-0.94)\end{array}$ & $-5.01-4.20$ & 331 of 500 & 0.023 \\
\hline
\end{tabular}

$I Q R$ interquartile range, $K T$ kidney transplantation, Epo erythropoietin, $S G A$ small for gestational age, $r h G H$ recombinant human growth hormone, $S D S$ standard deviation score, $e G F R$ estimated glomerular filtration rate, $P T H$ parathyroid hormone, $C R P$ C-reactive protein

${ }^{\mathrm{AA}}$ Annual average: AVERAGE of measurements in the year prior to annual assessment

${ }^{a}$ Descriptive statistic (non-repeated measurements) are given as median and interquartile range (25th-75th percentile)

${ }^{b}$ Repeated measurement (estimated marginal means) during the observation period are based on actual measurement or annual average values (AA), repeated measurements within the same individual (evaluated with the linear mixed model, random patients, and age cohorts) 
Significant decrease of mean eGFR began in the nonprior rhGH group 4 years post-KT, whereas in the rhGH group it began 8 years after KT (each $p<0.01$ ) resulting in a substantially higher eGFR 10 years after KT in the latter group $\left(69 \mathrm{ml} / \mathrm{min} / 1.73 \mathrm{~m}^{2}\right.$ versus $46 \mathrm{ml} / \mathrm{min} / 1.73$ $\mathrm{m}^{2}, p<0.01$ ) (Fig. 4). In both groups, post-transplant eGFR was associated with time after KT, steroid dosage, and circulating hemoglobin levels (each $p<0.01$, Table 3), whereas bicarbonate levels were positively associated with post-transplant eGFR only in the nonprior rhGH group $(p<0.05)$. The rhGH group had lower steroid exposure than those without prior rhGH treatment $(p<0.05)$ (Table 1, Fig. 5). Likewise, mean C-reactive protein (CRP) levels were lower in the rhGH group $(2.08 \mathrm{mg} / \mathrm{l}$ versus $5.59 \mathrm{mg} / \mathrm{l}, p<0.05)$. By contrast, mean PTH and plasma $\mathrm{HCO}_{3}$ levels were comparable in both groups (Table 1).

\section{Adjusted anthropometric z-scores in patients with and without prior rhGH treatment}

After adjusting anthropometric data for potential confounders (including age at which CKD stage 5 was reached, age at $\mathrm{KT}$, average daily steroid dosage, $\mathrm{pH}$ value, time after $\mathrm{KT}$, and average eGFR, bicarbonate, and hemoglobin levels during the preceding year), significant differences between groups were limited to sitting height $z$-scores (Table 2).

\section{Discussion}

This study shows that treatment of children with rhGH in the pre-transplant period was associated with several long-term beneficial effects after transplantation, some of which were unexpected. rhGH not only improved growth and maturation after KT but was also associated with better long-term transplant function, and lower degree of anemia and inflammation. Our data confirm the limited potential for substantial catch-up growth after KT and support the concept of timely initiation of rhGH treatment prior to KT in children with CKD and persisting short stature.

Growth failure is a hallmark of pediatric CKD, especially CKD stage 5 [3, 25], as also exhibited in this young CKD stage 5 population with mostly congenital CKD in which short stature was noted in approximately $2 / 3$ of patients. In about $35 \%$ of patients, treatment with rhGH was commenced prior to transplantation due to persistent short stature as recommended by current guidelines [10, 26]. Consequently, mean height $z$-scores at the time of KT did not differ between children with or without prior rhGH treatment. After KT, rhGH treatment was initiated in $18 \%$ of patients without prior rhGH treatment but in none of the rhGH group. Nevertheless, post-transplant growth was superior in the latter group. This is even more remarkable since these patients, who spent longer time on dialysis and less frequently underwent living related KT were burdened with conditions associated with poor growth outcome [27, 28].

The prospective assessment of post-transplant changes in linear body dimensions of both groups displayed disproportionate short stature with predominant impairment of leg length and rather preserved trunk length, which is in line with previous studies [21]. This is known to result in a significantly elevated sitting height index compared to healthy children [2]. After KT, superior height gain in the prior rhGH group occurred after an initial better preservation of sitting height followed by an improved long-term catch-up growth with increasing leg length. We previously demonstrated that KT preferentially stimulates trunk growth in young children (age $<4$ years) and leg growth in older children resulting in harmonization of body proportions [8]. This reversible variation in the sizes of body segments known as phenotypic plasticity seems beneficial for the organism in adapting to changes in living conditions or illness [29]. The present study suggests that pre-treatment with rhGH may prime the body to undergo phenotypic plasticity after KT and thereby helps to harmonize body proportions in these patients. As a consequence, the percentage of patients with normal height after KT was substantially higher in the rhGH group compared to that in the non-prior rhGH group which was most pronounced at 7 years after KT $(88.9 \%$ versus $54.3 \%$ ) corresponding to a mean age of 12 years.

With the typical prepubertal peak of linear growth occurring 1 year later in the non-prior rhGH group, our results suggest delayed onset of puberty and/or reduced pubertal height gain in these patients. Similar differences were observed with respect to sexual maturation. Menarche occurred timely in the rhGH group but was delayed by approximately 1 year in the non-prior rhGH group. Previous studies showed that longer duration of CKD, corticosteroid use, and lower GFR as well as shorter stature were associated with delayed menarche [30], and that girls with delayed menarche had lower bone mass density [31], which is in line with our results. Taken together, our data suggest that pre-treatment with rhGH improves growth as well as sexual and skeletal maturation after KT.

How does pre-treatment with rhGH impact on post-transplant growth and maturation? Evidence in this regard comes from two prospective studies investigating the effects of rhGH treatment on bone histology and matrix mineralization in short children on dialysis [32,33]. Both studies showed that rhGH not only improved growth in these patients, but also normalized bone formation rates as well as bone matrix mineralization irrespective of the type of histologic feature, e.g., abnormal bone turnover, mineralization, and/or volume, 
Fig. 1 Mean hemoglobin blood concentrations in 146 pediatric kidney transplant recipients with (solid lines, $n=52$ ) and without (broken lines, $n=94$ ) treatment with recombinant human growth hormone (rhGH) prior to kidney transplantation (KT) during the pre-transplant period. The label -1 refers to measurements collected in the year prior to KT

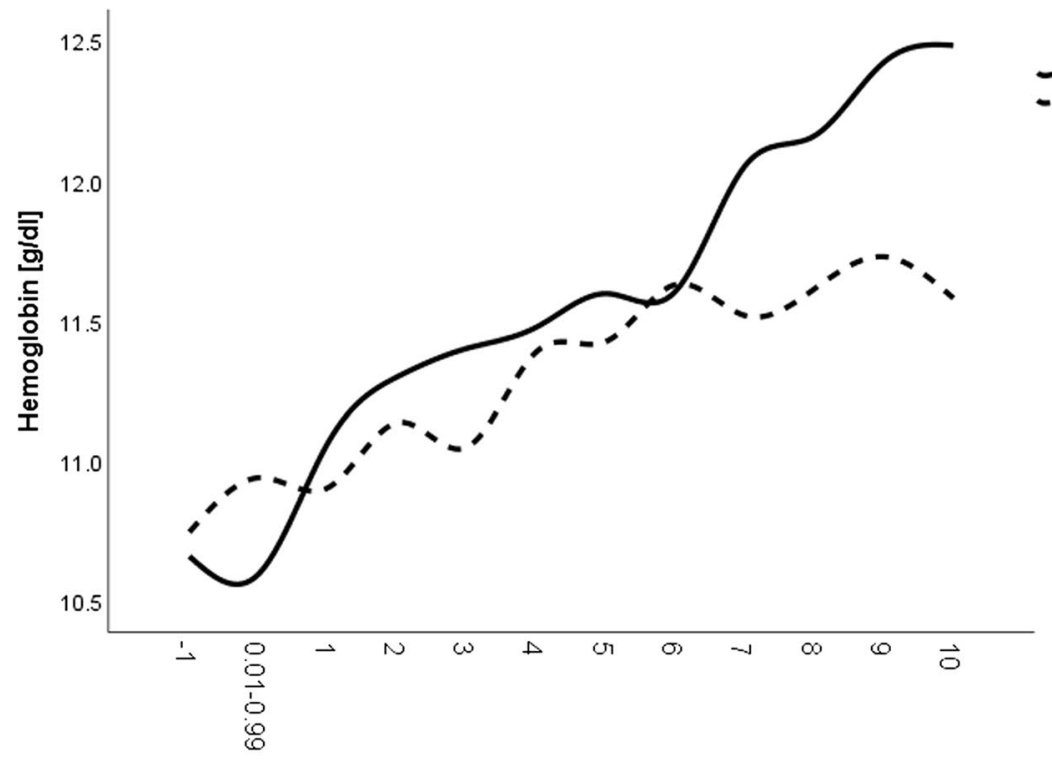

Time after transplantation [years]

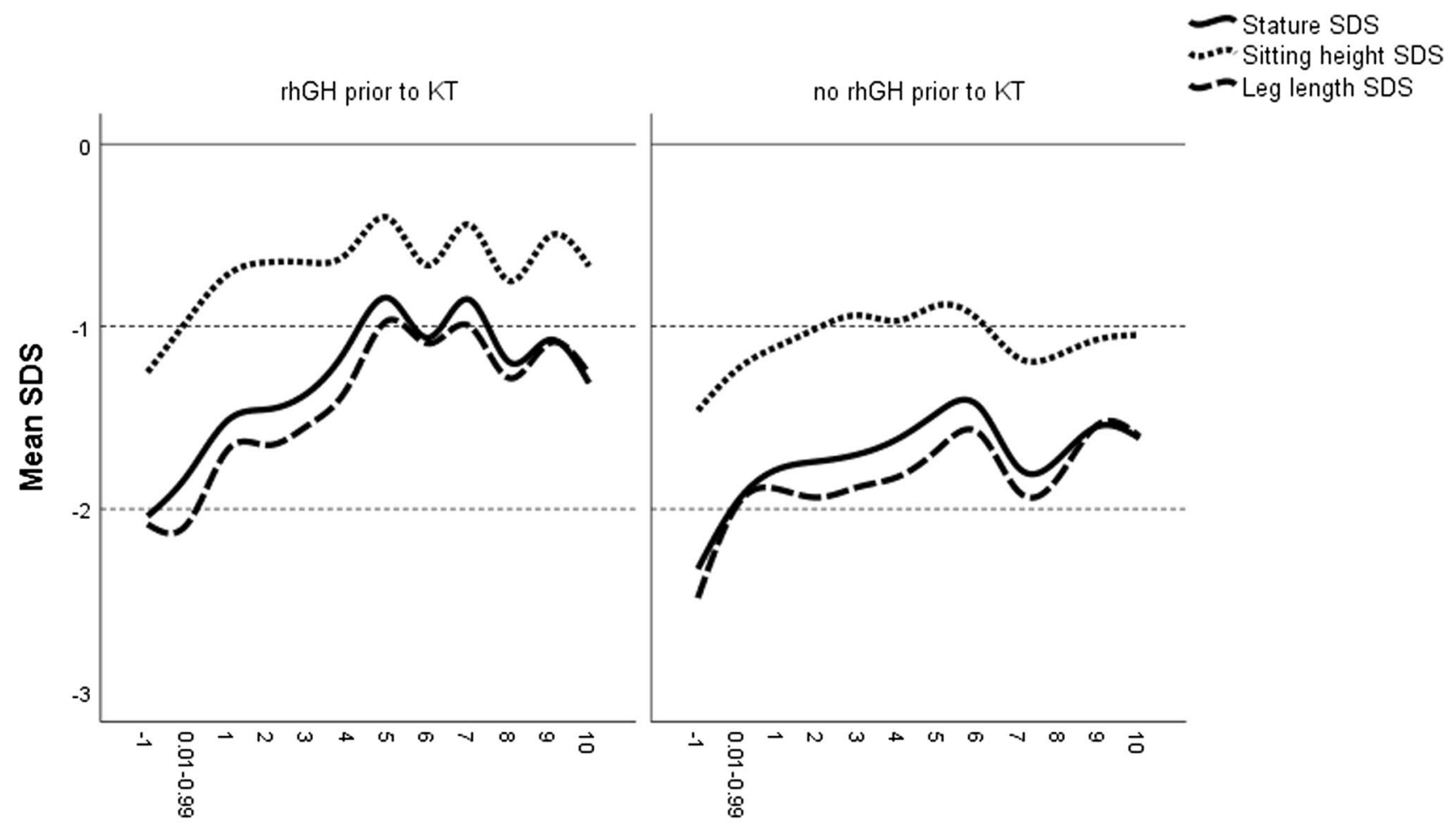

Time after transplantation [years]

Fig. 2 Post-transplant growth in 146 prepubertal children with (left, $n=52$ ) and without (right, $n=94$ ) treatment with recombinant human growth hormone (rhGH) prior to kidney transplantation (KT). Mean $z$-scores for height, sitting height, and leg length are given. The lower dotted horizontal line refers to the lower normal range $(-2.0$ $\mathrm{SD}$ score). The label -1 refers to measurements collected in the year prior to KT 
Table. 2 Nonadjusted and adjusted anthropometric parameters in prepubertal kidney allograft recipients who received rhGH before KT or not

\begin{tabular}{|c|c|c|c|c|c|c|c|c|c|}
\hline & Parameter & Stature SDS & $p$ value & Leg length SDS & $p$ value & Sitting height SDS & $p$ value & $\begin{array}{l}\text { Sitting height } \\
\text { index SDS }\end{array}$ & $p$ value \\
\hline \multirow[t]{3}{*}{$A$} & Non-adjusted & & & & & & & & \\
\hline & rhGH prior to $\mathrm{KT}$ & $\begin{array}{l}-1.33(-1.58 \\
\text { to }-1.08)\end{array}$ & 0.049 & $\begin{array}{c}-1.47(-1.72 \\
\text { to }-1.22)\end{array}$ & 0.081 & $\begin{array}{c}-0.71(-0.95 \\
\text { to }-0.47)\end{array}$ & 0.026 & $1.20(0.92$ to 1.47$)$ & 0.937 \\
\hline & $\begin{array}{l}\text { No rhGH prior } \\
\text { to KT }\end{array}$ & $\begin{array}{c}-1.68(-1.92 \\
\text { to }-1.43)\end{array}$ & & $\begin{array}{c}-1.79(-2.04 \\
\text { to }-1.53)\end{array}$ & & $\begin{array}{c}-1.08(-1.31 \\
\text { to }-0.85)\end{array}$ & & $1.18(0.95$ to 1.41$)$ & \\
\hline \multirow[t]{3}{*}{$B$} & Adjusted & & & & & & & & \\
\hline & rhGH prior to $\mathrm{KT}$ & $\begin{array}{c}-1.34(-1.65 \\
\text { to }-1.03)\end{array}$ & 0.136 & $\begin{array}{c}-1.49(-1.76 \\
\text { to }-1.22)\end{array}$ & 0.154 & $\begin{array}{c}-0.67(-0.92 \\
\text { to }-0.41)\end{array}$ & 0.046 & $1.21(0.92$ to 1.49$)$ & 0.849 \\
\hline & $\begin{array}{l}\text { No rhGH prior } \\
\text { to } \mathrm{KT}\end{array}$ & $\begin{array}{l}-1.64(-1.90 \\
\text { to }-1.39)\end{array}$ & & $\begin{array}{c}-1.78(-2.08 \\
\text { to }-1.49)\end{array}$ & & $\begin{array}{c}-1.03(-1.28 \\
\text { to }-0.78)\end{array}$ & & $1.24(0.98$ to 1.51$)$ & \\
\hline
\end{tabular}

A: Non-adjusted-Data are presented as SD scores (SDS), estimated marginal means (95\% confidence intervals). $p$ values are based on the linearly independent pairwise comparisons among the estimated marginal means

B: Adjusted-Data are presented as estimated marginal means (95\% confidence intervals); age at chronic kidney disease stage 5, age at KT, average daily steroid dosage in $\mathrm{mg}$ per $\mathrm{kg}$ per analyzed year, time after $\mathrm{KT}$, $\mathrm{pH}$ values, hemoglobin average of last year, $\mathrm{HCO}_{3}$ average of last year and eGFR; $p$ values are based on the linearly independent pairwise comparisons among the estimated marginal means

$S D S$ standard deviation score, $K T$ kidney transplantation, $r h G H$ recombinant human growth hormone, $e G F R$ estimated glomerular filtration rate

Fig. 3 Mean bone age delay in 146 pediatric kidney transplant recipients with (solid lines, $n=52$ ) and without (broken lines, $n=94$ ) treatment with recombinant human growth hormone (rhGH) prior to kidney transplantation (KT). The label -1 refers to measurements collected in the year prior to KT

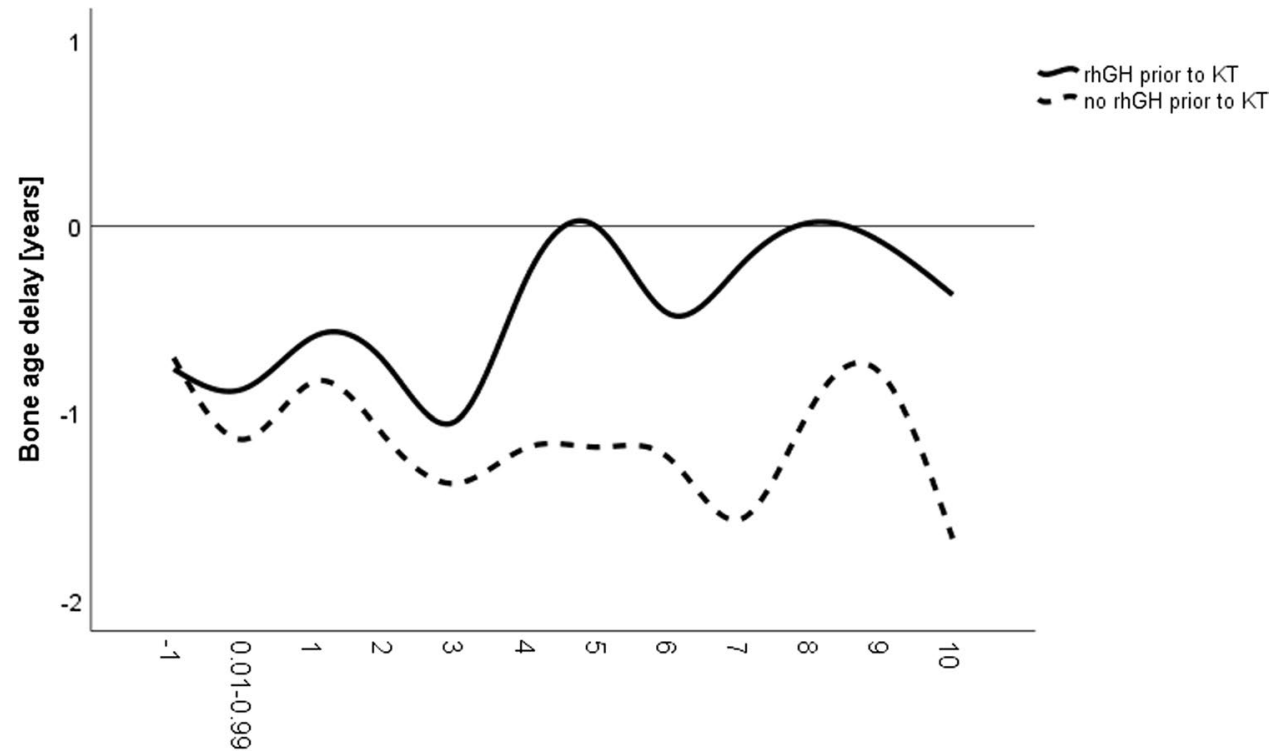

Time after transplantation [ years]

whereas no such changes were noted in controls. Therefore, pre-treatment with rhGH also might have improved bone quality in the present study and thereby prepared the bone for optimal post-transplant growth compared to patients without prior rhGH treatment.

Other important factors known to affect post-transplant growth including allograft function and steroid exposure need to be considered as well. Long-term transplant function in pediatric kidney allograft recipients is influenced by the quality of the transplant itself, with better results with living related donors, recipient-related factors such as
HLA-matching and HLA-immunization and the immunosuppressive regimen [1, 34, 35]. In the present study, the frequency of living related KT was lower in the rhGH group compared to the non-prior rhGH group. This is most likely due to the fact that patients for whom living-related transplantation is not an option in the near future are known to spend longer time on dialysis treatment [36], further exacerbating growth impairment. In those cases, physicians and families are more likely to initiate rhGH treatment. Despite this, long-term transplant function was superior in the rhGH group compared to that in the non-prior rhGH group. 
Fig. 4 Mean estimated glomerular filtration rates in 146 pediatric kidney transplant recipients with (solid lines, $n=52$ ) and without (broken lines, $n=94$ ) treatment with recombinant human growth hormone (rhGH) during the pre-transplant period. The label -1 refers to measurements collected in the year prior to KT. KT, kidney transplantation, eGFR, estimated glomerular filtration rate

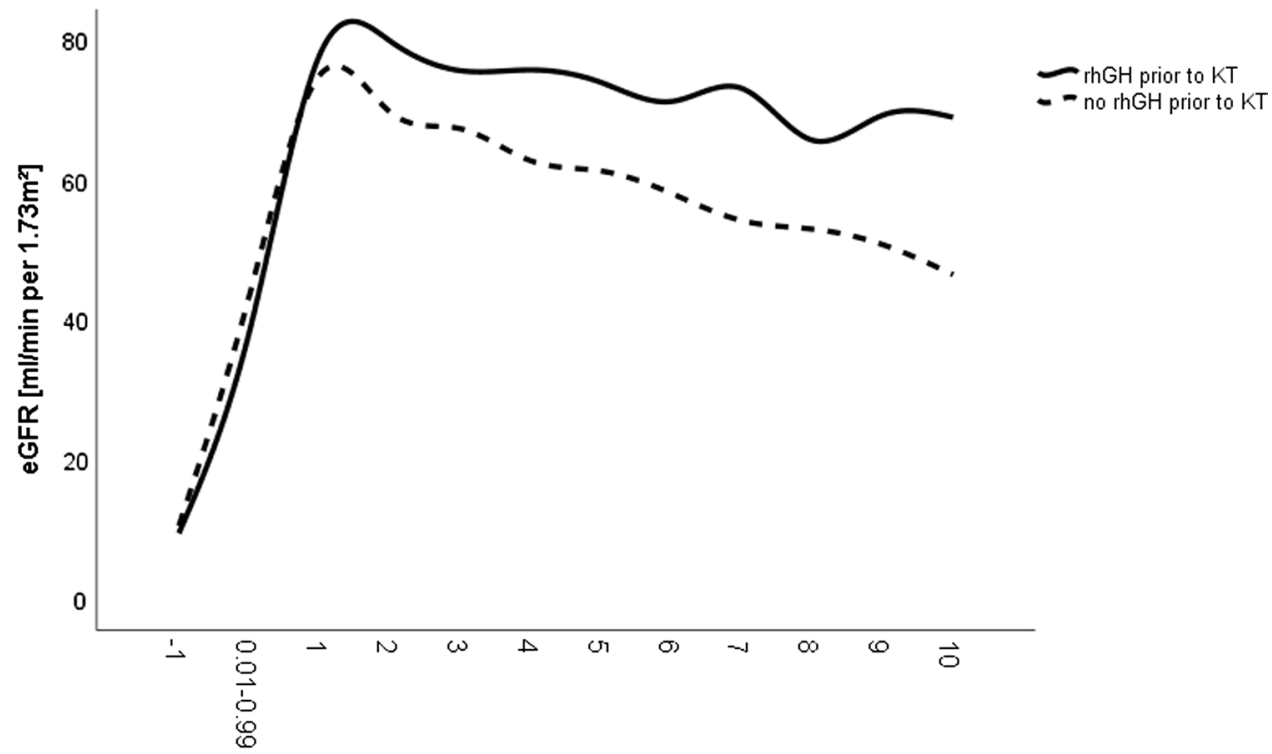

Time after transplantation [years]

Table. 3 Clinical predictors of transplant function

\begin{tabular}{|c|c|c|c|c|}
\hline Parameter & eGFR: rhGH prior to $\mathrm{KT}$ & $p$ value & eGFR: No rhGH prior to KT & $p$ value \\
\hline Age at stage 5 CKD (in year) & $0.11(-4.56$ to 4.79$)$ & 0.961 & $4.37(-3.99$ to 12.72$)$ & 0.301 \\
\hline Age at KT (in years) & $-1.59(-7.14$ to 3.96$)$ & 0.567 & $-5.90(-15.16$ to 3.35$)$ & 0.209 \\
\hline Time after KT (in years) & $-2.96(-3.69$ to -2.23$)$ & 0.000 & $-2.39(-2.75$ to -2.02$)$ & 0.000 \\
\hline Steroid dosage (in $\mathrm{mg} / \mathrm{kg}$ ) & $-99.14(-133.20$ to -65.09$)$ & 0.000 & $-60.92(-87.03$ to -34.81$)$ & 0.000 \\
\hline Hemoglobin (in $\left.10^{*} \mathrm{~g} / \mathrm{dl}\right)^{\mathrm{AA}}$ & $4.27(2.79$ to 5.75$)$ & 0.000 & $1.84(0.77$ to 2.92$)$ & 0.001 \\
\hline Plasma $\mathrm{HCO}_{3}$ (in $\left.10^{*} \mathrm{mmol} / \mathrm{l}\right)^{\mathrm{AA}}$ & $0.03(-1.08$ to 1.14$)$ & 0.957 & 0.85 (0.11 to 1.59$)$ & 0.024 \\
\hline
\end{tabular}

$e G F R$ estimated glomerular filtration rate, $K T$ kidney transplantation, $C K D$ chronic kidney disease

${ }^{\mathrm{AA}}$ Annual average

Fig. 5 Mean daily prednisolone dosages in 146 pediatric kidney transplant recipients with (solid lines, $n=52$ ) and without (broken lines, $n=94$ ) treatment with recombinant human growth hormone $(\mathrm{rhGH})$ prior to kidney transplantation (KT). The label-1 refers to measurements collected in the year prior to KT

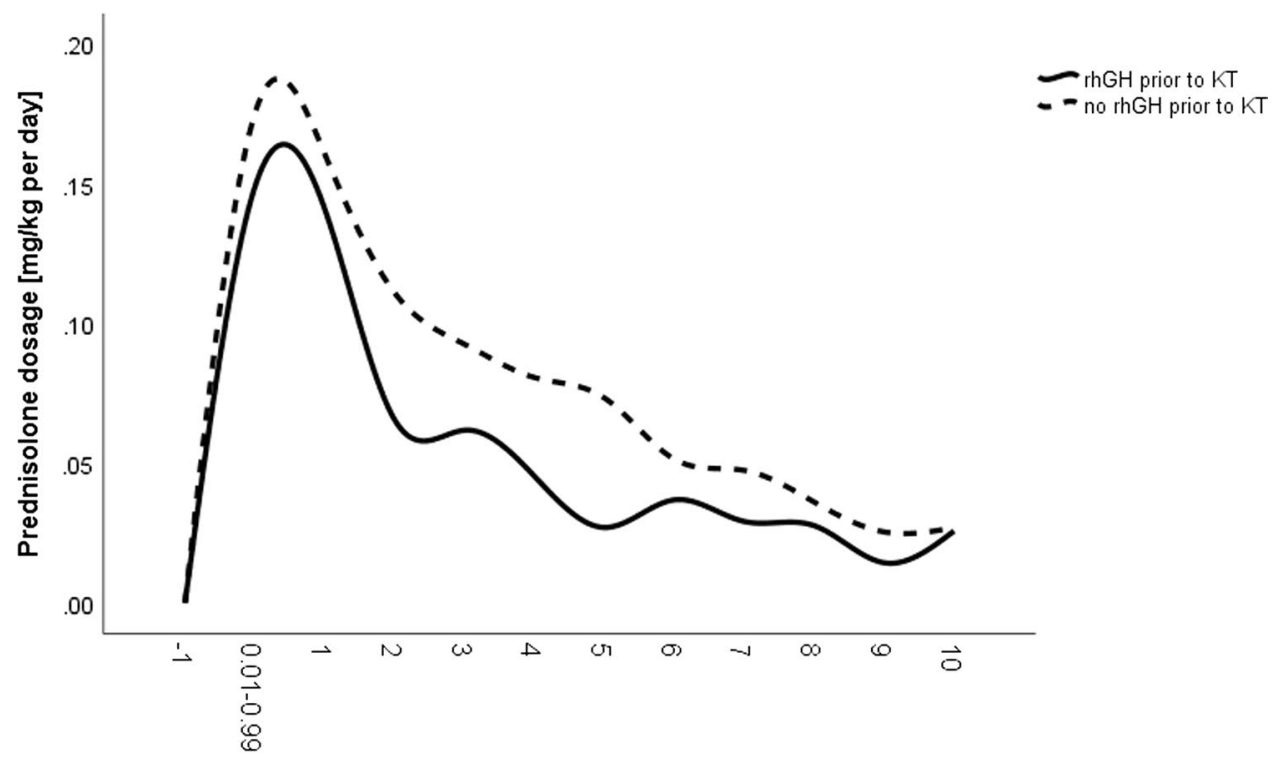

Time after transplantation [years] 
Although, in this observational study the primary immunosuppressive regimens did not generally differ between patients with or without prior rhGH treatment, the latter group received a substantially higher steroid exposure, which may at least partly explain the inferior growth outcome in this group. Lower steroid exposure in the rhGH group may be the consequence of better graft function facilitating steroid minimizing/withdrawal in these patients.

Elevated CRP levels were noted in the non-prior rhGH group but not in the rhGH group. C-reactive protein is a marker of the acute phase response to inflammation. Elevated circulating CRP $(>3 \mathrm{mg} / \mathrm{L})$ is associated with accelerated deterioration of graft function in kidney transplant recipients and thought to reflect kidney inflammation due to subclinical rejection [37-41]. Therefore, the notion of significantly elevated CRP levels in the non-prior rhGH group may not only explain the higher frequency of anemia as a consequence of inflammation but also subclinical graft rejection in these patients which may contribute to the inferior long-term graft function.

Finally, growth hormone and its mediator insulin-like growth factor (IGF) 1 play an important role in immunoregulation. Immune cells such as $\mathrm{T}$ and $\mathrm{B}$ lymphocytes express GH and IGF receptors and are therefore targets of both GH and IGF1 which may act as local growth and differentiation factors [42] and may regulate cytokine reaction [43]. However, a meta-analysis found no elevated rejection rates or more rapid deterioration of graft function due to rhGH treatment in pediatric kidney allograft recipients [44]. Data on the immunomodulatory effects of rhGH in pediatric $\mathrm{CKD}$ patients prior to $\mathrm{KT}$ are lacking. In view of the superior graft function in patients with prior rhGH treatment in the present study, it is tempting to speculate that pre-treatment with rhGH might have modified the immune response to the kidney allograft positively. However, several potentially confounding factors such as HLA mismatch, HLA antibodies, non-steroid immunosuppressive therapies, and allograft biopsy results could not be addressed in our study. An analysis with inclusion of patients who received rhGH before, as well as after KT was performed in which there was no marked difference to the analysis which excluded those patients, possibly due to the small number of those patients $(n=9)$. Therefore, a dedicated analysis regarding impact of and reasons for rhGH treatment in patients before, as well as after transplantation, is an interesting subject for further research.

In conclusion, pre-KT rhGH treatment in pediatric kidney allograft recipients resulted in superior long-term growth outcome after KT compared to patients without prior rhGH treatment which was mainly due to improved leg growth as well as skeletal maturation. Our data suggest that treatment with rhGH in the pre-transplant period in CKD patients presenting with persistent short stature is not only useful to improve growth outcome, but rather induces manifold positive effects such as lower rates of inflammation and anemia as well as better preservation of transplant function.

Supplementary Information The online version contains supplementary material available at https://doi.org/10.1007/s00467-021-05222-5.

Acknowledgements We thank the patients and their families taking part in this study and appreciate the support of doctors and nurses responsible for patient care.

Author contribution M. Ž., C. J., and D. H. designed the study. M. Ž. performed anthropometric measurements. M. Ž., C. J., and L. P. performed the statistical analysis and interpreted the data. C. J., R. K., S. M., and M. Ž. collected clinical data. C. J., R. K., S. M., and M. Ž. wrote the first draft of the manuscript; M. Ž. and D. H. revised the manuscript. All authors critically reviewed the manuscript and approved the final version for publication.

Funding Open Access funding enabled and organized by Projekt DEAL. This study received internal funding from Hannover Medical School. The funder had no influence on the content of this study.

Data availability Data cannot be published as it is used in an ongoing study.

Code availability Not applicable

\section{Declarations}

Conflict of interest The authors declare no competing interests.

Open Access This article is licensed under a Creative Commons Attribution 4.0 International License, which permits use, sharing, adaptation, distribution and reproduction in any medium or format, as long as you give appropriate credit to the original author(s) and the source, provide a link to the Creative Commons licence, and indicate if changes were made. The images or other third party material in this article are included in the article's Creative Commons licence, unless indicated otherwise in a credit line to the material. If material is not included in the article's Creative Commons licence and your intended use is not permitted by statutory regulation or exceeds the permitted use, you will need to obtain permission directly from the copyright holder. To view a copy of this licence, visit http://creativecommons.org/licenses/by/4.0/.

\section{References}

1. Winterberg PD, Garro R (2019) Long-term outcomes of kidney transplantation in children. Pediatr Clin North Am 66:269-280

2. Franke D, Thomas L, Steffens R, Pavičić L, Gellermann J, Froede K, Querfeld U, Haffner D, Živičnjak M (2015) Patterns of growth after kidney transplantation among children with ESRD. Clin J Am Soc Nephrol 10:127-134

3. Bonthuis M, Groothoff JW, Ariceta G, Baiko S, Battelino N, Bjerre A, Cransberg K, Kolvek G, Maxwell H, Miteva P, Molchanova MS, Neuhaus TJ, Pape L, Reusz G, Rousset-Rouviere C, Sandes AR, Topaloglu R, Van Dyck M, Ylinen E, Zagozdzon I, Jager KJ, Harambat J (2020) Growth patterns after kidney transplantation in european children over the past 25 years: An ESPN/ ERA-EDTA registry study. Transplantation 104:137-144 
4. Fine RN, Martz K, Stablein D (2010) What have 20 years of data from the north american pediatric renal transplant cooperative study taught us about growth following renal transplantation in infants, children, and adolescents with end-stage renal disease? Pediatr Nephrol 25:739-746

5. Franke D, Winkel S, Gellermann J, Querfeld U, Pape L, Ehrich JHH, Haffner D, Pavičić L, Zivičnjak M (2013) Growth and maturation improvement in children on renal replacement therapy over the past 20 years. Pediatr Nephrol 28:2043-2051

6. Tsampalieros A, Knoll GA, Molnar AO, Fergusson N, Fergusson DA (2017) Corticosteroid use and growth after pediatric solid organ transplantation: a systematic review and meta-analysis. Transplantation 101:694-703

7. Franke D, Alakan H, Pavičić L, Gellermann J, Müller D, Querfeld U, Haffner D, Živičnjak M (2013) Birth parameters and parental height predict growth outcome in children with chronic kidney disease. Pediatr Nephrol 28:2335-2341

8. Grohs J, Rebling R, Froede K, Hmeidi K, Pavičić L, Gellermann J, Müller D, Querfeld U, Haffner D, Živičnjak M (2021) Determinants of growth after kidney transplantation in prepubertal children. Pediatr Nephrol 36:1871-1880

9. Santos F, Díaz-Anadón L, Ordóñez FA, Haffner D (2021) Bone disease in CKD in children. Calcif Tissue Int 108:423-438

10. Drube J, Wan M, Bonthuis M, Wühl E, Bacchetta J, Santos F, Grenda R, Edefonti A, Harambat J, Shroff R, Tönshoff B, Haffner D (2019) Clinical practice recommendations for growth hormone treatment in children with chronic kidney disease. Nat Rev Nephrol 15:577-589

11. van Huis M, Bonthuis M, Sahpazova E, Mencarelli F, Spasojević B, Reusz G, Caldas-Afonso A, Bjerre A, Baiko S, Vondrak K, Molchanova EA, Kolvek G, Zaikova N, Böhm M, Ariceta G, Jager KJ, Schaefer F, van Stralen KJ, Groothoff JW (2016) Considerable variations in growth hormone policy and prescription in paediatric end-stage renal disease across european countries-a report from the ESPN/ERA-EDTA registry. Nephrol Dial Transplant 31:609-619

12. Akchurin OM, Kogon AJ, Kumar J, Sethna CB, Hammad HT, Christos PJ, Mahan JD, Greenbaum LA, Woroniecki R (2017) Approach to growth hormone therapy in children with chronic kidney disease varies across North America: the Midwest Pediatric Nephrology Consortium report. BMC Nephrol 18:181

13. Akchurin OM, Schneider MF, Mulqueen L, Brooks ER, Langman CB, Greenbaum LA, Furth SL, Moxey-Mims M, Warady BA, Kaskel FJ, Skversky AL (2014) Medication adherence and growth in children with CKD. Clin J Am Soc Nephrol 9:1519-1525

14. Greenbaum LA, Hidalgo G, Chand D, Chiang M, Dell K, Kump T, Peschansky L, Smith HK, Boyle M, Kopf M, Metz LC, Kamel M, Mahan JD (2008) Obstacles to the prescribing of growth hormone in children with chronic kidney disease. Pediatr Nephrol 23:1531-1535

15. Mehls O, Fine RN (2013) Growth hormone treatment after renal transplantation: a promising but underused chance to improve growth. Pediatr Nephrol 28:1-4

16. Haffner D (2020) Strategies for optimizing growth in children with chronic kidney disease. Front Pediatr 8:399

17. Tanner JM, Whitehouse RH (1976) Clinical longitudinal standards for height, weight, height velocity, weight velocity, and stages of puberty. Arch Dis Child 51:170-179

18. De Souza VC, Rabilloud M, Cochat P, Selistre L, Hadj-Aissa A, Kassai B, Ranchin B, Berg U, Herthelius M, Dubourg L (2012) Schwartz formula: is one k-coefficient adequate for all children? PLoS One 7:e53439

19. Voigt M, Schneider KT, Jährig K (1996) Analysis of a 1992 birth sample in Germany. 1: new percentile values of the body weight of newborn infants. Geburtshilfe Frauenheilkd 56:550-558
20. Atkinson MA, Warady BA (2018) Anemia in chronic kidney disease. Pediatr Nephrol 33:227-238

21. Zivicnjak M, Franke D, Filler G, Haffner D, Froede K, Nissel R, Haase S, Offner G, Ehrich JH, Querfeld U (2006) Growth impairment shows an age-dependent pattern in boys with chronic kidney disease. Pediatr Nephrol 22:420-429

22. Weiner JS, Lourie JA (1981) Practical human biology. Academic Press London Inc

23. Zivicnjak M, Narancić NS, Szirovicza L, Franke D, Hrenović J, Bisof V (2003) Gender-specific growth patterns for stature, sitting height and limbs length in Croatian children and youth (3 to 18 years of age). Coll Antropol 27:321-334

24. Zivicnjak M, Smolej Narancić N, Szirovicza L, Franke D, Hrenović J, Bisof V, Tomas Z, Skarić-Jurić T (2008) Genderspecific growth patterns of transversal body dimensions in croatian children and youth ( 2 to 18 years of age). Coll Antropol 32:419-431

25. Chua A, Cramer C, Moudgil A, Martz K, Smith J, Blydt-Hansen T, Neu A, Dharnidharka VR (2019) Kidney transplant practice patterns and outcome benchmarks over 30 years: the 2018 report of the NAPRTCS. Pediatr Transplant 23:e13597

26. Mahan JD, Warady BA (2006) Assessment and treatment of short stature in pediatric patients with chronic kidney disease: a consensus statement. Pediatr Nephrol 21:917-930

27. Harambat J, Bonthuis M, van Stralen KJ, Ariceta G, Battelino N, Bjerre A, Jahnukainen T, Leroy V, Reusz G, Sandes AR, Sinha MD, Groothoff JW, Combe C, Jager KJ, Verrina E, Schaefer F (2014) Adult height in patients with advanced CKD requiring renal replacement therapy during childhood. Clin J Am Soc Nephrol 9:92-99

28. Pape L, Ehrich JHH, Zivicnjak M, Offner G (2005) Growth in children after kidney transplantation with living related donor graft or cadaveric graft. Lancet 366:151-153

29. Price TD, Qvarnström A, Irwin DE (2003) The role of phenotypic plasticity in driving genetic evolution. Proc Biol Sci 270:1433-1440

30. Kim HS, Ng DK, Matheson MB, Atkinson MA, Warady BA, Furth SL, Ruebner RL (2020) Delayed menarche in girls with chronic kidney disease and the association with short stature. Pediatr Nephrol 35:1471-1475

31. Chevalley T, Bonjour J, Ferrari S, Rizzoli R (2008) Influence of age at menarche on forearm bone microstructure in healthy young women. J Clin Endocrinol Metab 93:2594-2601

32. Bacchetta J, Ranchin B, Demède D, Allard L (2013) The consequences of pediatric renal transplantation on bone metabolism and growth. Curr Opin Organ Transplant 18:555-562

33. Nawrot-Wawrzyniak K, Misof BM, Roschger P, PańczykTomaszewska M, Ziółkowska H, Klaushofer K, Fratzl-Zelman N (2013) Changes in bone matrix mineralization after growth hormone treatment in children and adolescents with chronic kidney failure treated by dialysis: a paired biopsy study. Am J Kidney Dis 61:767-777

34. Chandar J, Chen L, Defreitas M, Ciancio G, Burke G (2021) Donor considerations in pediatric kidney transplantation. Pediatr Nephrol 36:245-257

35. Kim JJ, Fuggle SV, Marks SD (2021) Does HLA matching matter in the modern era of renal transplantation? Pediatr Nephrol 36:31-40

36. Francis A, Johnson DW, Melk A, Foster BJ, Blazek K, Craig JC, Wong G (2020) Survival after kidney transplantation during childhood and adolescence. Clin J Am Soc Nephrol 15:392-400

37. García-Carro C, Dörje C, Åsberg A, Midtvedt K, Scott H, Reinholt FP, Holdaas H, Reisaeter AV, Seron D (2018) Kidney allograft subclinical rejection modulates systemic inflammation measured by $\mathrm{C}$-reactive protein at 1 year after transplantation. Clin Transplant 32:e13196 
38. Roshdy A, El-Khatib MM, Rizk MN, El-Shehaby AM (2012) CRP and acute renal rejection: a marker to the point. Int Urol Nephrol 44:1251-1255

39. do Nascimentoghizonipereira Luiza, Tedesco-Silva H, KochNogueira PC (2020) Acute rejection in pediatric renal transplantation: retrospective study of epidemiology, risk factors, and impact on renal function. Pediatr Transplant 25:e13856

40. García-Carro C, Dörje C, Åsberg A, Midtvedt K, Scott H, Reinholt FP, Holdaas H, Seron D, Reisæter AV (2017) Inflammation in early kidney allograft surveillance biopsies with and without associated tubulointerstitial chronic damage as a predictor of fibrosis progression and development of de novo donor specific antibodies. Transplantation 101:1410-1415

41. van Ree RM, Oterdoom LH, de Vries Aiko P. J., Gansevoort RT, van der Heide Jaap J. Homan, van Son WJ, Ploeg RJ, de Jong PE, Gans ROB, Bakker SJL (2007) Elevated levels of C-reactive protein independently predict accelerated deterioration of graft function in renal transplant recipients. Nephrol Dial Transplant 22:246-253

42. van Buul-Offers SC, Kooijman R (1998) The role of growth hormone and insulin-like growth factors in the immune system. Cell Mol Life Sci 54:1083-1094

43. Meazza C, Pagani S, Travaglino P, Bozzola M (2004) Effect of growth hormone $(\mathrm{GH})$ on the immune system. Pediatr Endocrinol Rev 1(Suppl 3):490-495

44. Wu Y, Cheng W, Yang X, Xiang B (2013) Growth hormone improves growth in pediatric renal transplant recipients-a systemic review and meta-analysis of randomized controlled trials. Pediatr Nephrol 28:129-133

Publisher's note Springer Nature remains neutral with regard to jurisdictional claims in published maps and institutional affiliations. 